\title{
Muscular effects of vitamin D in young athletes and non-athletes and in the elderly
}

\author{
Nikolaos E. Koundourakis, Pavlina D. Avgoustinaki, Niki Malliaraki, Andrew N. Margioris \\ Department of Clinical Chemistry, School of Medicine, University of Crete, Heraklion, Greece
}

\begin{abstract}
Muscles are major targets of vitamin D. Exposure of skeletal muscles to vitamin D induces the expression of multiple myogenic transcription factors enhancing muscle cell proliferation and differentiation. At the same time vitamin $D$ suppresses the expression of myostatin, a negative regulator of muscle mass. Moreover, vitamin D increases the number of type II or fast twitch muscle cells and in particular that of type IIA cells, while its deficiency causes type IIA cell atrophy. Furthermore, vitamin D supplementation in young males with low vitamin D levels increases the percentage of type IIA fibers in muscles, causing an increase in muscular high power output. Vitamin D levels are strongly associated with exercise performance in athletes and physically active individuals. In the elderly and in adults below the age of 65 , several studies have established a close association between vitamin $D$ levels and neuromuscular coordination. The aim of this review is to appraise our current understanding of the significance of vitamin $D$ on muscular performance in both older and frail individuals as well as in younger adults, athletes or non-athletes with regard to both ordinary everyday musculoskeletal tasks and peak athletic performance.
\end{abstract}

Key words: Athletic performance, Bone fractures, Muscle physiology, Physical activity, Rate of falls, Sarcopenia, Vitamin D

\section{BASICS ASPECTS OF SKELETAL MUSCLE PHYSIOLOGY}

Muscle cells are elongated and cylindrical in shape and are surrounded by a basal lamina of insulating collagen. In the space between muscle cells and their basal lamina there are several types of satellite cells that play a regulatory role in the growth, maintenance

\section{Address for correspondence:}

Andrew N. Margioris, M.D, Ph.D., Professor Emeritus, School of Medicine, University of Crete, Greece;

E-mail: margiori@uoc.gr

Received: 08-07-2016, Accepted: 07-11-2016 and repair of muscle cells. Each muscle cell contains myofibrils, bundles of several types of proteins organized into repeating microanatomical structures known as sarcomeres, which are the structural units making up the contractile machinery of muscle cells. A sarcomere is comprised of two types of protein filaments: tick filaments mainly composed of the protein myosin and thin filaments composed of the protein actin. Groups of tens to hundreds of muscle cells are packed together into parallel bundles known as fascicles which are wrapped in connective tissue, the perimysium, while bundles of fascicles composing a particular muscle are wrapped by the epimysium. 
The muscle motor unit: A motor unit is composed of a motor neuron and the muscle cells it activates, usually between ten to a couple of thousand. All cells of a motor unit contract at the same time. The primary neurotransmitter in the muscle motor units is acetylcholine which is synthesized by the motor neurons, packed within the synaptic vesicles located in the bulb at the end of the axon and secreted in the synaptic gap in a large and complex terminal formation called the motor end plate (or neuromuscular junction) located in proximity to the axon terminal bulb. The motor end plate contains the acetylcholine receptors, with acetylcholinesterase limiting the duration of the action of acetylcholine. Following muscle cell contraction, a refractory period ensues while the muscle cell pumps out sodium, thereby repolarizing the cell. When an impulse reaches the muscle cell, it induces a reaction within each sarcomere between the actin and myosin filaments, causing the sliding of these filaments and thus contraction. More specifically, the depolarization of a muscle cell induces a forward movement of myosin filament pulling the actin filaments towards the centre of the sarcomere, a process taking place simultaneously in the sarcomeres of a muscle cell, thus shortening all of them.

\section{The troponins}

These proteins play multiple roles within the muscle cells. Troponin I is the protein that plays the most crucial role, since it inhibits the attachment of myosin to actin. When a muscle cell is stimulated, calcium channels open in the sarcoplasmic reticulum and free calcium ions attached to the troponins, this ending their blocking effect on contraction and allowing actin and myosin to bind to each other. Relaxation occurs when stimulation of nerve cells ends and, as a result, calcium ions are pumped back into the sarcoplasmic reticulum: this permits troponin I to block the link between actin and myosin so that they return to their unbound state, thereby causing the muscle cell to relax.

\section{The two major types of muscle cells}

There are two main types of muscle cells: type I or slow twitch and type II or fast twitch. Type I muscle cells, referred to as "slow twitch oxidative cells", are characterized by low power production but high endurance capacity. The metabolism of type I is mainly aerobic, obtaining its energy from oxidative phosphorolation via the Krebs cycle: this requires
ATP and $\mathrm{O} 2$ and thus generates more vascularity and a large quantity of mitochondria and myoglobin. These muscle cells are, in fact, essential for endurance exercise, as for instance in distance running, since they are characterized by low strength and slow speed of contraction. Type I muscle cells, which are red because of their thick network of capillaries, give the muscles their characteristic red color. Type I muscle cells carry more oxygen and sustain aerobic activity for long periods of time, using fats or carbohydrates as fuel, but produce little force.

Type II, the fast twitch muscle, has three major subtypes (IIA, IIX and IIB) that vary in both contractile speed and force generated. Type IIA muscle cells are identified as "fast twitch oxidative" and exhibit qualities between those of type I and type IIB, while type IIB are exclusively "fast twitch glycolytic" characterized by high power - low endurance fibers. Type II muscle cells obtain their energy anaerobically via the glycolytic pathway typically involved in high strength and speed contractions, as in sprinting, generating large force per cross-sectional area but being prone to rapid fatigue. Type II contribute most to muscular strength and have greater potential for increase in mass. Type IIB is purely anaerobic, glycolytic and white because of the fewer capillaries, not many mitochondria and a lower amount of myoglobin. In small animals it is the main fast muscle type, which accounts for the pale color of their flesh.

\section{BASIC ASPECTS OF VITAMIN D BIOLOGY}

In humans, approximately $90 \%$ of the daily requirements for vitamin D come from an endogenous synthesis in the skin following exposure to ultraviolet sunrays, our skin converting 7-dehydroxy-cholesterol into vitamin D3 or cholecalciferol. The endogenous production of vitamin $\mathrm{D}$ depends on the seasonal variation of sun luminosity (insolation), duration of exposure, area of skin exposed, use of sunscreens, skin pigmentation and the age-dependent ability of the skin to synthesize vitamin D as well as the availability of the precursor 7-dehydrocholesterol in the skin.

Dietary intake, on the other hand, covers only about $10 \%$ of the daily requirements in vitamin $\mathrm{D}$, this vitamin being rare in most types of food, with the exception of fatty fish, eggs, cod liver oil and, of course, the degree of fortification of dairy products 
with vitamin $\mathrm{D}$ by the manufacturer. Dietary vitamin D may come in the form of vitamin D3 or as D2 or ergocalciferol from vegetables. It should be noted that vitamin D-fortified dairy products may not contain the levels of vitamin D indicated on the label. One mcg (40 IU) of exogenous vitamin D per day elevates the circulating levels of 25(OH)D by only $0.4-1.6 \mathrm{ng} /$ $\mathrm{mL}$ or $1-4 \mathrm{nmol} / \mathrm{L}$. Vitamin D3 is converted in the liver into $25(\mathrm{OH}) \mathrm{D}$ (calcidiol) and subsequently into its biologically active form, 1,25(OH)2-Vit D (calcitriol) in the kidneys and is absorbed to a much lesser degree in the lymph nodes. Levels below $10 \mathrm{ng} / \mathrm{ml}$ or $25 \mathrm{nmol} / \mathrm{L}$ indicate vitamin D insufficiency (mainly evaluated by the levels of circulating parathyroid hormone, PTH, which acts as a biomarker). Vitamin $\mathrm{D}$ deficiency is considered to be between 10 and 30 $\mathrm{ng} / \mathrm{ml}$ or $25-75 \mathrm{nmol} / \mathrm{L}$ and optimal levels above 30 $\mathrm{ng} / \mathrm{ml}$ or $90 \mathrm{nmol} / \mathrm{L}$, and more than $40 \mathrm{ng} / \mathrm{ml}$ or 100 $\mathrm{nmol} / \mathrm{L}$ for those above the age of 70 .

The activated form of vitamin D, i.e. 1,25-dihydroxyvitamin $\mathrm{D}$, exerts its biological effects by binding to the nuclear vitamin D receptor (VDR), which induces the heterodimerisation of activated VDR with the retinoic-receptor, thus forming the VDR/ retinoic-receptor/cofactor complex. This complex binds to vitamin $\mathrm{D}$ response elements affecting gene expression.

The biological effects of vitamin $\mathrm{D}$ can be grouped into two major categories: 1) those associated with calcium homeostasis (calcium absorption from the gastrointestinal track, induction of osteoclast maturation resulting in acceleration of bone remodelling turnover, calcium deposition in newly-formed bone, reduction of PTH synthesis, etc.), and 2) those effects not associated with bone homeostasis, including its anti-inflammatory effects, inter alia, suppression of inteleukin 6, suppression of cell proliferation of neoplastic cells, ${ }^{1}$ induction of insulin synthesis and secretion from the beta cells, suppression of rennin synthesis and its effects on the neuromuscular cells, the subject of this review.

\section{EFFECTS OF VITAMIN D ON SKELETAL MUSCLES}

The association between vitamin $\mathrm{D}$ and muscular physiology was first examined in the sixties when proximal myopathy was found to be associated with vitamin D deficiency. ${ }^{1}$ It is now well-established that vitamin $\mathrm{D}$ is an integral part of skeletal muscle physiology. ${ }^{2}$ Muscles are major targets of vitamin D, expressing large numbers of vitamin D receptors. ${ }^{3}$ In muscles, vitamin D affects cell proliferation and differentiation and the transport of calcium and phosphate across muscle cell membranes, while it modulates phospholipid metabolism. ${ }^{4}$ Vitamin D additionally suppresses the expression of myostatin, a negative regulator of muscle mass, while it up-regulates the expression of follistatin and insulin-like growth factor 2..$^{5-7}$ Exposure of skeletal muscles to vitamin D induces the expression of a number of myogenic transcription factors, ${ }^{8}$ including the marker of myogenic differentiation, fetal myosin, as well as of the neural cell adhesion molecule, Bcl-2, insulin-like growth factor-I, fibroblast growth factor and the retinoblastoma protein. ${ }^{9}$ What is more, vitamin $\mathrm{D}$ affects myogenic differentiation protein 1 (MYOD1), a helix-loop-helix family of transcription factor of the myogenic factors subfamily. MYOD1 regulates muscle cell differentiation by inducing cell cycle arrest, a prerequisite for myogenic initiation. MYOD1 is moreover crucial for the initiation of muscle regeneration by causing an increase of the cross-sectional area of skeletal muscle fibers. ${ }^{10}$ Vitamin D signaling has additionally been reported to alter the expression of myotubular sizes, indicating a direct positive effect on the contractile filaments and thus muscle strength, while it prevents muscular degeneration and reverses myalgia. ${ }^{11,12}$ Last but not least, vitamin $\mathrm{D}$ accelerates muscle recovery from the stress of intense exercise. ${ }^{13}$

\section{EFFECTS OF VITAMIN D ON MUSCLE CELL TYPES}

Vitamin D affects the diameter and number of type II, or fast twitch, muscle cells, and in particular that of type IIA cells. In severe vitamin D deficiency, proximal myopathy is observed characterized by type IIA cell atrophy. Vitamin D supplementation in young males increases the percentage of type IIA fibers in muscles, causing an increase in muscular high power output. Vitamin D-mediated induction of muscle protein synthesis and myogenesis results in muscles of higher quality and quantity, which is translated into increased muscle strength since 
there is a linear association between muscle mass and strength. Hypertrophy of type IIB muscle fibers results in enhanced neuromuscular performance. These types of fibers are major determinants of the explosive type of human strength that results in high power output. It is of note that type II muscle fibers induce fast muscle contraction velocity and higher force compared to type I muscle fibers. ${ }^{14}$ Therefore, anaerobic maximal intensity short-burst activities, such as jumping, sprinting, acceleration, deceleration and change of direction, which are of crucial importance for the majority of athletic events, are highly related to type II muscle cells. Interestingly, the maintenance of type II muscle cells is important for the elderly as well as for athletes. Reversal of type II fiber atrophy as a result of vitamin D supplementation is thought to account for an approximately $20 \%$ lower risk of falling. Although vitamin D deficiency induces the atrophy of type II fibers in these individuals, it also enables fat infiltration and consequently fibrosis which are important factors in muscular physiology and are crucial predictors of muscle function in older subjects. ${ }^{15}$

\section{EFFECTS OF VITAMIN D ON THE MYOCARDIUM AND VASCULAR SMOOTH MUSCLES}

Vitamin D receptors are expressed in the human myocardium as well as in vascular smooth muscles and the endothelium. Vitamin D affects the structural remodeling of cardiac muscle and vascular tissues ${ }^{16}$ and results in improvements in flow-mediated dilation and blood pressure. ${ }^{17}$ Improved cardiac muscle function has been reported in patients with severe vitamin D deficiency following supplementation with the vitamin. In animal studies, vitamin $\mathrm{D}$ directly alters myocyte contractility affecting their relaxation time, a crucial component of cardiac diastolic function. Vitamin D has in addition been found to regulate the function of calcium channels in cardiac myocytes, providing a rapid influx of calcium into cells promoting myocyte contractility. ${ }^{18}$ Furthermore, vitamin D inhibits the proliferation of cardiomyoblasts by promoting cell-cycle arrest and enhances the formation of cardiomyotubes without inducing apoptosis. Moreover, vitamin D attenuates left ventricular dysfunction in several animal models and in humans. ${ }^{19}$ Vitamin D also affects arterial stiffness and endothelial function, which are crucial components of aerobic and anaerobic exercise performance and the ability to perform most daily activities. Data from both animal and human studies show that vitamin D is a suppressor of the rennin-angiotensin-aldosterone system (RAAS). More specifically, vitamin D suppresses RAA activity by lowering the gene expression of rennin..$^{20}$ It is interesting that elevated parathyroid hormone $(\mathrm{PTH})$ levels in secondary hyperparathyroidism induce left ventricular hypertrophy, which is ameliorated by vitamin D supplementation..$^{21}$ Low levels of vitamin D correlate with increased arterial stiffness and endothelial dysfunction in humans. ${ }^{22,23}$ Vitamin D has in addition been reported to exert anti-atherogenic effects via promoting HDL transport and inhibiting cholesterol uptake by the macrophages and the formation of foam cells. ${ }^{24}$ Vitamin D deficiency is associated with vascular inflammation and atherogenesis. ${ }^{25}$ Vitamin D supplementation suppresses inflammation via inhibition of prostaglandin and cyclooxygenase pathways, up-regulation of anti-inflammatory cytokines, decrease of cytokine-mediated expression of adhesion molecules, reduction of matrix metalloproteinase and down-regulation of the RAA. Finally, the third National Health and Nutrition Examination Survey (NHANES III) demonstrated a strong association between low vitamin D levels and key cardiovascular risk factors following adjustment for multiple variables. ${ }^{26}$

\section{EFFECTS OF VITAMIN D ON THE NERVOUS SYSTEM}

Vitamin D exerts multiple effects on the nervous system, while its deficiency has been associated with several neurological diseases, including multiple sclerosis, amyotrophic lateral sclerosis and Parkinson's disease. Several clinical trials suggest that vitamin D supplementation may exert a protective effect on these neurological conditions, albeit these studies appear to be inconclusive. However, it is now well-documented that vitamin D affects all aspects of cognition.

Impairment of cognitive faculties with advancing age is strongly and independently associated with decreased physical mobility, increased risk for falls and serious fall-related injuries..$^{27,28}$ This is because low vitamin D serum levels correlate with cognitive 
defects, executive function impairments and dysfunction of the frontal-subcortical neuronal circuits..$^{29,30}$

It is noteworthy that vitamin $\mathrm{D}$ receptors are present throughout the brain, including the primary motor cortex. ${ }^{31,32}$ They have been identified in both neuronal and glial cells within the cortex, in deep grey matter, in the cerebellum, in brainstem nuclei and in the spinal cord and the ventricular system. Furthermore, the enzyme $1, \alpha$-hydroxylase, the activator of vitamin D precursors, is also present in the brain. ${ }^{33,34}$ Vitamin $\mathrm{D}$ levels are associated with the conductance velocity of motor neurons and neurotransmission mediated by dopamine, serotonin, acetylcholine, GABA and the catecholamines. Vitamin D additionally affects neuronal differentiation, maturation and growth, its levels correlating to the levels of several neurotrophic factors, including nerve growth factors (NGF) and that of neurotrophyns, which play crucial roles in the maintenance and growth of neurons. ${ }^{35,36}$ In addition, vitamin D exerts direct neuroprotective effects via the synthesis of proteins binding calcium ions. Proper levels of neuronal calcium are critical since their excess may result in the formation of reactive oxygen species (ROS) which lead to neuronal damage. Vitamin D levels are in fact inversely associated with oxidative stress which damages the brain, leading to neuronal apoptosis or necrosis. ${ }^{37}$ What is more, vitamin $\mathrm{D}$ affects neuroplasiticity, a process via which neural synapses and pathways are adapted to the needs of environmental and behavioral demands, adjusting the brain to noxious stimuli diseases or environmental cues. $^{38,39}$ Moreover, vitamin D affects GABAergic neurons in the motor cortex ${ }^{40}$ GABAergic function being the principal "brake" within the brain affecting muscle relaxation via the corticospinal neurons. ${ }^{41}$ Of particular note, GABAergic, serotonin and dopamine neurons are crucial in muscular coordination and the avoidance of central fatigue, ${ }^{42}$ a high ratio of serotonin to dopamine positively impacting exercise performance because of serotonin's effect on the general feeling of tiredness and the perceptions of effort. ${ }^{43}$

\section{EFFECTS OF VITAMIN D ON NOCIRECEPTORS}

Low vitamin D levels may indirectly exert detrimental effects on kinetic performance via its involvement in the function of nocireceptors, i.e. the sensory nerve cells that identify noxious stimuli and subsequently send appropriate signals to the brain. When these receptors transmit pain signals, an inhibitory physical response is activated, malfunction of which results in kinetic instability and maladaptation. Vitamin D affects nocireceptors which have an abundance of vitamin D receptors and 1a-hydroxylase. ${ }^{44,45}$ Animal studies have shown that vitamin D depletion causes nociceptive hyperinnervation and hypersensitivity within deep muscle tissue and, as a result, loss of balance, without affecting muscle strength or the cutaneous nociceptive response. Defects of nociceptive innervation and/or hypersensitivity within deep muscles results in difficulties in assessing myalgia during physical activity. In vitamin $\mathrm{D}$ deficient individuals this is enhanced, leading to difficulties in muscular coordination and performance. Finally, reaction times, which play a crucial role in the rate of falls, deteriorate with age. Vitamin D improves reaction times and thus physical and exercise performance. ${ }^{46,47}$

\section{POSITIVE STUDIES, I.E. STUDIES SHOWING A STRONG ASSOCIATION BETWEEN VITAMIN D LEVELS AND MUSCLE STRENGTH IN ADULT NON-ATHLETES AND THE ELDERLY}

Vitamin D levels correlate with several indices of neuromuscular performance in day-to-day life. In the past, myopathy and muscle weakness in rickets and osteomalacia was associated with severe vitamin D deficiency. ${ }^{48}$ Since then, several cross-sectional observations and longitudinal studies have established a close association between vitamin D and several parameters of neuromuscular performance. The majority of these studies have been performed in the elderly, although similar data have also been reported in adults below the age of $65^{49}$ and in the young. ${ }^{50,51}$ In the CHIANTI study, physical performance was assessed in more than 900 individuals aged 65 or older and physical performance was assessed at baseline. ${ }^{52} \mathrm{~A}$ significant association was found between low levels of vitamin D and overall poor physical performance as assessed by the handgrip strength test and a short physical performance battery of tests, including the ability to stand up from a chair and the ability to maintain balance in progressively more challenging positions. Elderly individuals with serum vitamin D levels less than $10 \mathrm{ng} / \mathrm{ml}$ performed worse compared 
to age-matched individuals with levels above 10. Muscle strength assessed by handgrip was significantly greater in subjects with vitamin D levels higher than $20 \mathrm{ng} / \mathrm{ml}$ compared to those with lower levels. The use of handgrip strength is a reliable test to stratify adults at risk of impaired mobility and falls. Elderly individuals with higher levels of vitamin D exhibit better lower extremity muscle performance compared to age-matched individuals with lower levels of vitamin D. ${ }^{53}$ Similar data were obtained in the Rancho Bernardo Study cohort. ${ }^{54}$ Likewise, a longitudinal survey of community-dwelling Japanese older women showed that those with higher levels of vitamin D responded better in a three-month exercise program compared to those with lower levels. ${ }^{55}$

The association between vitamin D levels and the rate of physical performance declines with advancing age, a factor that has also been assessed. ${ }^{56} \mathrm{An}$ acceleration of the rate of physical performance with advancing age was associated with vitamin $\mathrm{D}$ levels lower than $20 \mathrm{ng} / \mathrm{ml}$ compared to age-matched peers with levels higher than $30 \mathrm{ng} / \mathrm{ml}$. In another study in elderly females over the age of 65 , the association between vitamin D levels and muscle function, strength and physical performance was evaluated using a walking-speed test, a standing balance and a sit-to-stand test. ${ }^{57}$ Vitamin D levels above $20 \mathrm{ng} / \mathrm{ml}$ were associated with better muscle strength, whereas levels below $8 \mathrm{ng} / \mathrm{ml}$ were associated with the poorest strength performance. In yet another study, the authors documented a strong association between vitamin D levels and muscle power, force, velocity and jump height in young adolescent girls. ${ }^{50}$ Similarly, a positive correlation between vitamin D serum levels and handgrip strength was documented in a population of 300 vitamin D sufficient Chinese adolescent girls. ${ }^{51}$

\section{NEGATIVE STUDIES, I.E. STUDIES SHOWING NO ASSOCIATION BETWEEN VITAMIN D LEVELS AND MUSCLE STRENGTH IN NON-ATHLETES AND THE ELDERLY}

Stockton et al were unable to document an association between vitamin D levels and lower extremity muscle strength in individuals with vitamin D levels above $10 \mathrm{ng} / \mathrm{ml} .{ }^{58}$ Similarly, no association was found between muscular performance and vitamin D levels in older Hawaiian women of Japanese ancestry, a population known for their very low rate of falls, high dietary intake of vitamin $\mathrm{D}$ and daily exposure to ample sunlight. ${ }^{59}$ Indeed, in this population, among whom the mean vitamin D level was $32 \mathrm{ng} / \mathrm{ml}$, with no individual being in a vitamin D deficiency state, the authors were unable to document any association between vitamin D levels and muscle strength, rate of falls and the quantity of daily activities. It was concluded that the absence of a relationship was due to the high levels of vitamin $\mathrm{D}$ that these women displayed at baseline. Indeed, it now appears that vitamin D levels may correlate with physical performance only in the lower levels range. Corroborating this hypothesis are the findings of a recent study in which in a population-based sample of adult men with levels of vitamin $\mathrm{D}$ in serum above $20 \mathrm{ng} / \mathrm{ml}$ there was no association between vitamin $\mathrm{D}$ and muscle strength or physical performance, after adjusting for several lifestyle factors. ${ }^{60}$ However, in a challenging study by Matheï et al, ${ }^{61}$ the Belfrail study, conducted in elderly individuals of more than 80 years of age and with an $80 \%$ prevalence of vitamin D insufficiency, no correlation was evident between vitamin $\mathrm{D}$ levels and physical performance, as assessed by gait speed, the hand grip test and a static balance test. In agreement with this negative study, several studies conducted in younger persons also failed to document an association between vitamin $\mathrm{D}$ levels and muscular strength. Thus, in young women no association was found between vitamin D levels and handgrip strength. ${ }^{62}$ Similar data were reported by the OFELY study. ${ }^{63}$

\section{ERGOMETRIC EFFECT OF VITAMIN D SUPPLEMENTATION}

A large number of studies have found that vitamin D supplementation improves several indices of ergometrics i.e. muscular performance, including balance, neuromuscular coordination, gait speed, hand grip, body sway, overall muscle strength and muscular response to training in both the elderly and younger adults. ${ }^{54,65}$ More specifically, an association has been documented between vitamin $\mathrm{D}$ and physical performance of 100 healthy elderly Chilean subjects aged 70 years or more. ${ }^{66}$ Vitamin D supplementation improved gait speed and body sway as well as improving muscle strength response to training. 
Similar findings were observed in elderly women, mean age 85 years, where vitamin $\mathrm{D}$ supplementation improved muscular performance and decreased the rate of falls. ${ }^{67}$

In a randomized double-blind controlled trial by Moreira-Pfrimer et al, ${ }^{61}$ it was reported that treatment of vitamin D deficiency increased lower limb muscle strength in institutionalized older individuals independently of their physical activity. ${ }^{68}$ Indeed, vitamin D supplementation resulted in improved isometric muscle strength and strength of hip flexors, knee extensors and upper muscles. Vitamin D supplementation In 242 community-dwelling seniors in Bad Pyrmont, Germany (latitude $52^{\circ} \mathrm{N}$ ), and Graz, Austria (latitude $46^{\circ} \mathrm{N}$ ), resulted in a significant improvement in the rate of falls, quadriceps strength and body sway needed to perform the timed up and go (TUG) test, which assesses a person's mobility and requires both static and dynamic balance. It uses the time that a person takes to rise from a chair, walk three metres, turn around, walk back to the chair and sit down. ${ }^{69}$ However, it should be noted that a recent meta-analysis of this work detected major inconsistencies in the text and tables ${ }^{70}$ which were addressed by the first author. ${ }^{71}$ The effect of vitamin D supplementation on hand grip strength has been examined in a number of studies, none of which was able to detect any significant effects in males in contrast to women. ${ }^{72,73}$ Gender differences in the response to vitamin D supplementation may explain these discrepancies. ${ }^{74}$

\section{EFFECT OF VITAMIN D SUPPLEMENTATION ON THE EFFICACY OF EXERCISE TRAINING IN NON-ATHLETES AND THE ELDERLY}

The effect of vitamin D supplementation on resistance training was examined by Agergaard et $\mathrm{al}^{3}$ in randomized young and elderly untrained males in a study at latitudes with low sunlight (DecemberApril, $\left.56^{\circ} \mathrm{N}\right)$. All participants in the study followed a progressive resistance training program of the quadriceps muscles assessed by measurements of muscle hypertrophy, quadriceps isometric strength and muscle biopsies for fiber type morphology, expression of vitamin D receptors and myostatin. ${ }^{3}$ Vitamin D supplementation increased the percentage of fiber type IIa and decreased myostatin mRNA compared to par- allel controls. Vitamin D supplementation improved the muscular effects of resistance training (muscle strength evaluated by isokinetic dynamometry and percutaneous isometric electromyostimulation) in the older adults but failed to induce any changes in the younger males. It should be noted though that the younger individuals had quite high levels of serum vitamin D (mean $48 \mathrm{ng} / \mathrm{ml}$ ). In several other controlled randomized trials that have measured muscle strength in vitamin D supplemented persons, their age ranging from 18 to 40 years, a significant increase in upper and lower limb strength was repeatedly documented. ${ }^{75,76}$ The minor differences recorded may be attributed to the wide range of vitamin $\mathrm{D}$ supplements used in each study. ${ }^{77}$ Generally speaking, modest doses of vitamin D supplementation appear to be superior compared to much higher doses. ${ }^{77}$ Thus, vitamin D supplementation at daily doses of 800 to $1,000 \mathrm{IU}$ consistently demonstrated beneficial effects on strength and balance, ${ }^{78}$ vitamin D supplementation in general notably strengthening quadriceps power. ${ }^{79,80}$

It should be noted, however, that regarding the efficacy and the degree of the beneficial effects of vitamin $\mathrm{D}$ supplementation on muscle strength and balance as a general rule, it appears that the priorto-treatment levels of vitamin D are of paramount importance. Indeed, the higher the pretreatment levels, the lesser the magnitude of the benefits, i.e. even a small gain in muscle strength can be complemented through vitamin D supplementation. ${ }^{58}$

\section{ASSOCIATION BETWEEN LOW VITAMIN D LEVELS AND THE RISK OF FALLS AND FRACTURES IN THE ELDERLY}

The International Osteoporosis Foundation, the Endocrine Society and the US Preventive Services Task Force agree that low levels of vitamin D are directly associated with an increased incidence of falls and fractures in the elderly. ${ }^{81}$ Gerdhem et al ${ }^{82}$ have evaluated, in the prospective population-based OPRA study of elderly women, the association between vitamin D levels, fall-associated variables including muscle strength and fracture rates in these ambulatory women. ${ }^{82}$ They have found that low levels of vitamin D were strongly associated with lower levels of physical activity, gait speed and balance, 
while, moreover, levels of less than $20 \mathrm{ng} / \mathrm{ml}$ were associated with an increased risk of fractures. It has in fact has been suggested that the minimum level of serum vitamin $\mathrm{D}$ that prevents falls and fractures in the elderly seems to be around $24 \mathrm{ng} / \mathrm{ml}$. Higher levels than this do not appear to offer any additional beneficial effect regarding the risk of falling. ${ }^{81}$

Thus, most of the current literature data concur that vitamin D deficiency leads to myopathy, reduced muscle mass and strength, low exercise performance and an increased risk of falling, ${ }^{83}$ while higher vitamin D levels have been associated with improved balance, reduced frailty and disability, ${ }^{84,85}$ maintenance of functional independence ${ }^{86}$ and better mobility. ${ }^{53,87,88}$

Other major trials have also confirmed that vitamin D supplementation lowers the risk of falling and fractures in the elderly. Prince et $\mathrm{al}^{89}$ in a randomized, controlled trial in Australia evaluated women with at least one fall in a 12-month period and with a plasma 25-hyroxyvitamin D level $<24$ $\mathrm{ng} / \mathrm{mL}$. The authors suggested that elderly persons with a history of falling and vitamin D insufficiency living in sunny climates benefit from ergocalciferol supplementation resulting in a $19 \%$ reduction in the relative risk of falling, mostly in winter. Pfeifer et a ${ }^{90}$ demonstrated a reduction in falls of 27 to $39 \%$ in community-dwelling seniors supplemented with 800 IU vitamin D and calcium daily versus calcium alone. This drop in falls was correlated with an improvement in quadriceps strength and in the TUG test. Similarly, Zhu et al ${ }^{91}$ reported enhanced muscular strength and improved TUG test in the individuals within the lowest vitamin D quartile. These results are consistent with another study that showed a 49\% reduction in falls in elderly women from a geriatric ward supplemented with $800 \mathrm{IU}$ per day of vitamin D. Bischoff-Ferrari et a ${ }^{92}$ evaluated several studies involving men and women with an average age of 70 in whom vitamin D supplementation resulted in a significant $22 \%$ decrease in fall risk. In another report, vitamin D supplementation in homebound older subjects resulted in a significant decrease in the rate of falling compared to those randomized to placebo. ${ }^{93}$

It is of interest that in a recent report it was found that high doses of vitamin D supplementation may be counterproductive in preventing falls among the elderly. Specifically, the effectiveness of different doses of vitamin D supplementation were evaluated regarding the risk of functional decline in 200 community-dwelling men and women 70 years and older with a prior history of falls. A one-year followup showed that the incidence of falls was higher in the high vitamin dose group, i.e. those taking 60,000 IU per week compared to those taking 24,000 IU per week. The authors concluded that although the higher monthly dose of vitamin $\mathrm{D}$ was effective in reaching a threshold of at least $30 \mathrm{ng} / \mathrm{mL}$ of serum vitamin $\mathrm{D}$, it had no significant beneficial effects on muscle strength at the lower extremities and instead may have augmented the risk of falls compared to the lower dose. ${ }^{94}$

\section{VITAMIN D AND MOBILE INDEPENDENCE IN THE ELDERLY}

It is well documented that the maintenance of muscle strength and power in the elderly is crucial in preserving their kinetic ability and their mobile independence for the performance of all the physical activities needed. It is of note that in the elderly, mobility limitations in most reports is defined as a self-reported inability to walk a mile, climb stairs or perform housework. ${ }^{95}$ Maintenance of functional independence among the elderly depends on muscular performance, mental capabilities, bone structure, the cardiovascular system and, of course, vitamin D levels. ${ }^{96,97}$

The Barthel scale assesses the likelihood of the elderly to be able to live at home independently and, according to this scale, patients taking vitamin D supplements have a higher Barthel index. ${ }^{98}$ Barthel is an ordinal scale used to measure performance in activities of daily living (ADL). Ten variables of performance are measured, each rated on this scale with a given number of points assigned to each level or ranking. In fact, vitamin D levels appear to be the only relevant modifiable factor for the likelihood of recovering walking ability after hip fracture. ${ }^{99}$

\section{GEOGRAPHICAL LATITUDE AND INSOLATION ON EXERCISE PERFORMANCE}

Athletic performance parallels seasonal fluctuations of vitamin D levels, peaking in summer when vitamin D levels are the highest. ${ }^{100}$ Koch and Ra- 
schka, ${ }^{101}$ reviewing the German experience as to the seasonality of physical performance, confirmed that muscular strength and maximal oxygen uptake $\left(\mathrm{VO}_{2 \max }\right)$ peaked in late summer. Comparable findings were reported in the seventies in a study on the physical performance of a population of approximately 2000 Norwegian men showing seasonal variability peaking in summer. ${ }^{102}$ Similar data were reported in the eighties regarding the seasonal performance of the Swedish national track and field teams where $\mathrm{VO}_{2 \max }$ peaked in summer. ${ }^{103}$

The seasonal variation of vitamin D is a welldocumented phenomenon. ${ }^{104}$ In the winter months, endogenous vitamin $\mathrm{D}$ production is drastically reduced as a result of reduced exposure to UVB radiation, while it may be adequate in summer when exposure to UVB radiation promotes the endogenous synthesis of vitamin D synthesis in the skin, the principal source of this vitamin. Similar variations have been reported for athletes. In soccer players, the levels of serum vitamin D are "normal" in 50\% of athletes during summer, whereas it drops to $16 \%$ in winter. ${ }^{105}$ A study performed in a high latitude area (Laramie, WY $41.3^{\circ} \mathrm{N}$ ) revealed that the prevalence of "low" vitamin $\mathrm{D}$ was about $63 \%$ in winter compared to only $12 \%$ in autumn and $20 \%$ in spring in both indoor and outdoor athletes. ${ }^{104}$

Similar findings have been reported in a study conducted at higher latitudes (Ellensburg, WA $46.9^{\circ} \mathrm{N}$ ) using exclusively outdoor athletes. A percentage of $25 \%$ to $30 \%$ of the athletes were vitamin D insufficient during fall and winter. ${ }^{106}$ Morton et a ${ }^{13}$ also reported a significant drop of serum levels of vitamin D in a group of professional soccer players of the English Premier League at the latitude of $53^{\circ} \mathrm{N}$ between summer and winter. In agreement with these data were findings in professional soccer players in Spain training at a latitude of $37^{\circ} \mathrm{N}$ and showing a statistically significant reduction in serum levels of vitamin D from October to February. ${ }^{107}$

Although most authors attribute the peaking of athletic performance during the summer months to higher vitamin D levels, other authors disagree with this explanation and offer alternative causes for this well-documented seasonality. According to Morton et $\mathrm{al},{ }^{13}$ the higher physical performance in summer is a consequence of outdoor physical activity in the warmer weather which additionally results in exposure of athletes to higher levels of UAV, i.e. these authors see the two phenomena as parallel but independent. Furthermore, athletes participating in summer competitions such as track and field need to be in top condition during this period since most major competitions take place in summer. As a consequence, enhanced training and competition in summer would result in both better athletic performance and a parallel but independent rise of serum vitamin D levels. ${ }^{108}$ On the other hand, participants in other sports such as soccer, American football or basketball attain their best performance in winter, while in summer they recuperate resulting in a reduction and/or cessation of their training and to a deterioration of exercise performance and capacity. ${ }^{109}$ Nevertheless, even when controlling for seasonal fluctuations in time spent exercising, variation in wrist flexor strength and muscle trainability still correlated with seasonal variations of vitamin D levels.

\section{VITAMIN D LEVELS AND INDICES OF ATHLETIC PERFORMANCE IN SOCCER AND OTHER SPORTS}

There is a growing body of literature documenting a strong association between vitamin D levels and indices of exercise performance in athletes and in physically active populations. A recently published study from our laboratory ${ }^{109}$ reported a linear relationship between vitamin D levels and muscle strength as evaluated by squat jump (SJ), countermovement jump (CMJ), sprinting ability $(10 \mathrm{~m}$, and $20 \mathrm{~m})$, and $\mathrm{VO}_{2 \max }$ in non-supplemented professional soccer players. Our results are comparable with a number of other reports on a variety of sports, all showing that vitamin D levels are closely associated with muscle power, neuromuscular performance and aerobic endurance in athletes. ${ }^{110-112}$ Of note, Hamilton et $\mathrm{al}^{113}$ reported that vitamin D levels were not associated with lower limb isokinetic muscle function in soccer players, although those soccer players with lower levels of vitamin D exhibited a significantly lower torque in hamstring and quadriceps muscle groups compared to those with higher vitamin D levels, a finding suggesting that lower vitamin $\mathrm{D}$ levels are indeed associated with inferior muscular function during exercise. 
Regarding aerobic capacity and $\mathrm{VO}_{2 \max }$, large cross-sectional studies have shown that vitamin D levels correlate well with overall performance and cardiovascular fitness. Specifically, Mowry et al have found a positive correlation between baseline cardiorespiratory fitness, $\mathrm{VO}_{2 \max }$ and serum vitamin $\mathrm{D}$ levels in 16- to 24-year-old healthy athletic women. Similarly, a recent study in professional soccer players reported that $\mathrm{VO}_{2 \max }$ was significantly associated with vitamin D levels. ${ }^{111}$ Similar findings have been reported in young physically active individuals. ${ }^{112}$ Individuals who had vitamin D levels above the recommended limit of $35 \mathrm{ng} / \mathrm{mL}$, i.e. were vitamin D sufficient, were found to have significantly higher $\mathrm{VO}_{2 \max }$ values when compared with athletes whose vitamin D was below this cut-off point. Finally, Ardestani et al ${ }^{114}$ reported a close association between vitamin D levels and $\mathrm{VO}_{2 \max }$ in both men and women. Interestingly, this correlation was also evident in subjects with moderate levels of physical activity.

\section{STUDIES UNABLE TO DOCUMENT ANY CORRELATION BETWEEN VITAMIN D LEVELS AND ATHLETIC PERFORMANCE IN VARIOUS SPORTS}

A number of published reports fail to document any statistically significant correlation between indices of exercise performance and vitamin D levels. ${ }^{115}$ Thus, vitamin D levels did not appear to correlate with grip strength or swimming performance in adolescent swimmers ${ }^{116}$ nor with isokinetic peak torque during knee flexion and extension after adjusting for total body and lean mass in Qatar soccer players. ${ }^{113}$ Similarly, no association was observed between athletic performance and vitamin D levels in hockey players whose explosive strength during jumping was not associated with vitamin D levels nor with power production during the Wingate anaerobic test. ${ }^{115}$ Similarly, vitamin D levels were not associated with $\mathrm{VO}_{2 \text { peak }}$ in the skating treadmill tests of junior and collegiate male hockey players. The authors suggested that these findings could be the result of the fact that none of their players was vitamin D deficient. According to Wilson et al, ${ }^{117}$ worsening in aerobic capacity could result only in vitamin $\mathrm{D}$ deficient individuals. In the study by Fitzgerald et al, ${ }^{115}$ the authors reported that although $37.7 \%$ of their athletes had insufficient vitamin D levels, levels in the deficiency range were necessary for a compromise of cardiovascular fitness to ensue. Again, our opinion is that for vitamin D to statistically be able to affect muscle strength or aerobic capacity, serum levels should be in the insufficiency range since individual variations in muscular performance or aerobic capacity may hide individual dependence on vitamin D levels, the only way to overcome this problem being vitamin $\mathrm{D}$ supplementation.

\section{EFFECT OF VITAMIN D SUPPLEMENTATION ON ATHLETIC PERFORMANCE}

It is increasingly apparent that athletes need higher levels of vitamin D because of the elevated demands of their strenuous daily training, ${ }^{118}$ vitamin D exhibiting a positive linear relationship with ergometric evaluation of muscle strength. ${ }^{119}$ Vitamin D supplementation has moreover been demonstrated to augment athletic performance in vitamin D-deficient athletes. ${ }^{100}$ Early studies on collegiate athletes and students showed that cardiovascular fitness, muscle endurance and speed were enhanced following exposure to ultraviolet radiation. Historically, in 1938 Russian authors ${ }^{120}$ reported that sessions of ultraviolet irradiation improved speed in the 100-m dash in four students as compared with matched controls. The irradiated students had a 7.4\% increase in 100-dash times compared to only $1.7 \%$ of the controls, although both groups underwent the same exercise training. Subsequently, it was shown that UV irradiation twice a week for a period of six weeks resulted in a significant improvement in performance in the bike ergometer. ${ }^{121} \mathrm{UAV}$ treatment in college athletes also enhanced cardiovascular fitness, ${ }^{122}$ while it additionally improved reaction time in adolescent and adult individuals. ${ }^{123}$ Furthermore, a single exposure to UV irradiation increased strength, speed, aerobic performance and endurance in college women. ${ }^{124,125}$ Enhanced performance was moreover observed in the 30-yard dash of college women after 6-minute exposure to UV light. ${ }^{126}$

A randomized placebo-controlled study examined the effects of vitamin D3 supplementation on musculoskeletal performance ${ }^{127}$ in highly trained male professional soccer players. Approximately 60\% of the athletes on supplementation and $70 \%$ of the controls exhibited serum levels of vitamin D prior 
to treatment of $20 \mathrm{ng} / \mathrm{ml}$. Vitamin D supplementation increased serum vitamin D levels to $40 \mathrm{ng} / \mathrm{ml}$ and increased significantly the $10 \mathrm{~m}$ sprint time and vertical-jump compared to the placebo group. Similar data were obtained in athletes living at northerly latitudes $\left(\mathrm{UK}=53^{\circ} \mathrm{N}\right)$ who had low vitamin D levels $(<20 \mathrm{ng} / \mathrm{ml})$. Corroborating these data, Wyon et al ${ }^{128}$ reported enhanced neuromuscular performance in elite classical ballet dancers who in a study were placed on vitamin D supplementation, while isometric muscular strength and vertical jump height were measured pre- and post-intervention. A significant increase of isometric strength and vertical jump were observed. Interestingly, the intervention group also sustained significantly fewer injuries compared to the controls. In agreement with these data are the findings of another study from the same group. ${ }^{129}$ The authors examined the effect of vitamin D supplementation on muscle function using isokinetic dynamometry in male judoka athletes randomly allocated to vitamin D treatment or placebo. The former group had a significant increase in muscle strength.

It should be noted, however, that vitamin D supplementation does not improve athletic performance in individual athletes who have sufficient vitamin D levels prior to treatment. Thus, Close et a $\mathrm{l}^{130}$ examined the effects of vitamin D supplementation on several exercise performance indices in club-level athletes. Participants were randomized into those receiving placebo or vitamin D. No improvement of exercise performance was observed, most probably because none of the athletes had low vitamin D levels prior to treatment. ${ }^{130}$ The lack of any beneficial effect of vitamin D supplementation on athletes with adequate levels of vitamin D prior to treatment was also documented in reports involving rowers and football players. ${ }^{131,132}$

\section{THE EFFECTS OF VITAMIN D ON MUSCLES PARALLELS ITS EFFECTS ON TESTOSTERONE PRODUCTION}

It has been suggested by several small studies that vitamin D may be associated with testosterone levels and that vitamin D supplementation may boost the endogenous production of testosterone. If these observations are indeed true, we may attribute part of the beneficial effects of vitamin D on the neuromus- cular system to its beneficial effect on testosterone. However, the current literature data on this subject are limited and most are contradictory. Thus, in a large European Male Ageing Study, although free testosterone levels were lower and E(2) and LH levels higher in men with vitamin $\mathrm{D}$ deficiency, i.e. in men with $25(\mathrm{OH}) \mathrm{D}<50 \mathrm{nmol} / 1$, adjusting the data for health and lifestyle factors, no significant associations were evident. Furthermore, while a significant seasonal variation was evident in $25(\mathrm{OH}) \mathrm{D}$ levels, no corresponding variation of the reproductive hormones, SHBG or PTH, was present. ${ }^{133}$

It is of special note that only one other large observational study was published prior to the European Male Ageing Study designed to evaluate the possible association between $25(\mathrm{OH}) \mathrm{D}$ and testosterone levels in men. The authors found that serum 25(OH)D levels were independently associated with testosterone in a sample of 2299 men with a mean age of 62 years and that a parallel seasonal pattern of $25(\mathrm{OH}) \mathrm{D}$ and testosterone levels was present. However, the study population was highly biased since the subjects were not healthy, having hypertension, pre-existing coronary artery disease and diabetes, while the negative study consisted of essentially healthy community-dwelling males. ${ }^{134}$

In another study of 1362 male participants of the Health Professionals Follow-up Study selected for a nested case-control study on prostate cancer, $25(\mathrm{OH}) \mathrm{D}$ levels were associated with total and free testosterone reaching a plateau at higher levels. Again, this study also had a biased population. ${ }^{135}$

Moreover, studies with vitamin D supplementation are mostly negative or contradictory. For example, in a post hoc analysis of three small clinical trials of limited duration in men with normal baseline testosterone concentrations, supplementation with $2000 \mathrm{IU}$ of cholecalciferol daily was not associated with any increase in the circulating testosterone levels. ${ }^{136} \mathrm{By}$ contrast, in another small study vitamin D supplementation had a borderline effect on testosterone levels. ${ }^{137}$ Of interest however are two smaller studies, one in China and another in Korea, that found a positive correlation between $25(\mathrm{OH}) \mathrm{D}$ and testosterone, which showed a similar seasonal variation. Lower vitamin D levels were associated with a higher prevalence 
of hypogonadism in Chinese men. This association might, in part, be explained by adiposity and insulin resistance and warrants additional investigation. ${ }^{138,139}$

\section{VITAMIN D IN SARCOPENIA}

Sarcopenia is defined as a major loss of muscle mass and strength in older individuals to a degree of less than 2SD compared to that of the young. The prevalence of sarcopenia increases with age from 5 to $15 \%$ in persons between 60 and 70 years of age and up to $50 \%$ in persons older than 80 . The risk of falling doubles in sarcopenic individuals. ${ }^{140-143}$ Sarcopenia should not be confused with two other causes of muscle loss, cachexia and age-associated loss of muscle cells. Thus, severe cancer may cause cachexia or myopenia associated with the circulating cytokines and other tumor-produced factors affecting cell health and tissue renewal. In individuals with no cancer, sarcopenia appears to be the extreme end of an age-associated gradual loss of muscle mass starting at the age of 30 and accelerated by a sedentary lifestyle. Between ages 30-60, most adults exhibit a gradual loss of approximately a quarter of a $\mathrm{kg}$ of muscle mass per year, while at the same time gaining half a $\mathrm{kg}$ of fat. ${ }^{144-146}$

Histologically, sarcopenia is characterized by a decline in the number of type II fast twist muscle cells and a parallel increase in the number of type I slow twitch cells. Sarcopenia is additionally characterized by fat infiltration of muscles identified as myosteatosis or obese sarcopenia. DEXA, ultrasound, MRI and $\mathrm{CT}$ are useful in assessing muscle fat composition.

Several factors accelerate muscle loss with age, lack of exercise and a sedentary lifestyle as well as a parallel reduction of protein intake being thought to represent the principal inducing factors. Exercise is well-established as having trophic effects on muscle mass and function. Sarcopenia is negatively associated with the dietary intakes of energy and proteins in both genders. It should be noted that proteins act synergistically with exercise to increase muscle mass. Another factor contributing to the development of sarcopenia is the decline of testosterone levels. Testosterone activates protein synthesis in muscles and inhibits the maturation of pre-adipocyte progenitor cells present within muscles. Testosterone produc- tion declines gradually in males (around $1 \%$ per year after the 30th year of age) and in females at a much faster rate.

A strong association between serum vitamin D levels and sarcopenia has been documented in several studies. Indeed, sarcopenia is inversely associated with serum 25(OH)D levels in women and serum PTH in men. The likelihood of sarcopenia increases 1.46-fold because of the lowering of serum $25(\mathrm{OH}) \mathrm{D}$ by $10 \mathrm{ng} / \mathrm{mL}$. Furthermore, mice lacking the vitamin D receptor exhibit a sarcopenic skeletal muscle phenotype. It should also be mentioned that the density of vitamin D receptors in human muscle decline as a function of aging. ${ }^{147-150}$

\section{VITAMIN D ACCELERATES MUSCLE HEALING AMELIORATING THE INFLAMMATORY RESPONSE TO INJURIES}

Vitamin D affects both innate and adaptive immunity, vitamin receptors being present in most cells of the immune system, including Treg cells, neutrophils, dendritic cells, B cells and macrophages. Interestingly, several immune cells, including lymphocytes, hydroxylate $25(\mathrm{OH}) \mathrm{D}$ to its active form $1,25(\mathrm{OH}) 2$. Most of the effects of vitamin D on innate immunity are anti-inflammatory. In monocytes/macrophages, vitamin D suppresses the production of the inflammatory cytokines TNF-alpha, IL-1beta, IL-6 and IL-8. Vitamin D also suppresses TLR expression, the TLR transmembrane protein inducing the signaling cascade activating transcription factor $\mathrm{NF} \kappa \mathrm{B}$ and cytokine production, in immune cells and adipocytes. ${ }^{151,152}$

Intense exercise in conditioned athletes and demanding endurance sports damage skeletal muscle cells: this results in intramuscular inflammatory responses, namely, infiltration of neutrophils and macrophages into the damaged muscles and the local production of cytokines and chemokines. It is a process largely initiated by the damaged muscle cells which produce muscle-derived cytokines, the infiltrating neutrophils and monocytes/macrophages promoting muscle damage subsequent to muscle injury. Macrophages may also play a role in muscle repair and regeneration through growth factors and cytokine-mediated effects. Furthermore, muscle cells-derived nitric oxide inhibits inflammatory cell invasion into the healthy 
parts of muscles, while intramuscular immune cells remove cellular debris and protein fragments to facilitate subsequent muscle regeneration and healing. During the inflammatory phase, muscular pain is intensified and muscle strength declines, compromising athletic performance. Of particular note, because the inflammatory phase is crucial for the subsequent healing process, its pharmacological suppression may jeopardize it. Indeed, exercise-induced muscular inflammation initiates muscle repair, regeneration and growth involving activation and proliferation of satellite cells. The process of muscle recovery is characterized by the removal of the remaining cell debris, intense protein synthesis and myogenesis. ${ }^{153-156}$

Vitamin D ameliorates the inflammatory response following muscle injuries by suppressing the local production of tumor necrosis factor-alpha (TNF-alpha) and by blocking c-Jun N-terminal kinase and nuclear factor- $\kappa \mathrm{B}(\mathrm{NF}-\kappa \mathrm{B})$, i.e. the signaling pathways mediating the pro-inflammatory effects of TNF-alpha. Apart from its ameliorating effects on the inflammatory response, it has been shown that vitamin D moreover plays an important role in the recovery of muscles from injuries. Indeed, vitamin D stimulates the growth and proliferation of myocytes by moving phosphate into them. Vitamin D treatment improves markers of skeletal muscle damage including creatine kinase and lactate dehydrogenase. Vitamin D in addition exerts beneficial effects on injured tendons via matrix metalloproteinases and transforming growth factor- $\beta 3 .{ }^{157,158}$

\section{CONCLUSION}

Multiple randomized trials have established that serum vitamin D levels correlate well with muscular performance in young and old non-athletes, the rate of falls and fractures among elderly subjects and neuromuscular performance in professional athletes. Vitamin D affects multiple components of the neuromuscular axis as well several cognitive faculties. However, vitamin D supplementation benefits only individuals with "low levels" of vitamin D prior to treatment and has no effects on those with adequate serum levels. Finally, megadoses of vitamin D supplementation may have deleterious consequences for exercise performance, while they may also increase the rate of falls in the elderly.

\section{REFERENCES}

1. Park SY, Murphy SP, Wilkens LR, Nomura AM, Henderson BE, Kolonel LN, 2007 Calcium and vitamin D intake and risk of colorectal cancer: The multiethnic cohort study. Am J Epidemiol 165: 784-793.

2. Todd JJ, Pourshahidi LK, McSorley EM, Madigan SM, Magee PJ, 2015 Vitamin D: Recent advances and implications for athletes. Sports Med 45: 213-229.

3. Agergaard J, Trøstrup J, Uth J, et al, 2015 Does vitamin$\mathrm{D}$ intake during resistance training improve the skeletal muscle hypertrophic and strength response in young and elderly men? A randomized controlled trial. Nutr Metab (London) 30: 12-32.

4. Garay E, Jankowski P, Lizano P, et al, 2007 Calcitriol derivatives with two different side-chains at C-20. Part 4: Further chain modifications that alter VDR-dependent monocytic differentiation potency in human leukemia cells. Bioorg Med Chem 15: 4444-4455.

5. Pojednic RM, Ceglia L, 2014 The emerging biomolecular role of vitamin D in skeletal muscle. Exerc Sport Sci Rev 42: 76-81.

6. Artaza JN, Mehrotra R, Norris KC, 2009 Vitamin D and the cardiovascular system. Clin J Am Soc Nephrol 4: 1515-1522.

7. Moran DS, McClung JP, Kohen T, Lieberman HR, 2013 Vitamin D and physical performance. Sports Med 43: 601-611.

8. Garcia LA, King KK, Ferrini MG, Norris KC, Artaza JN, 2011 1,25(OH)2vitamin D3 stimulates myogenic differentiation by inhibiting cell proliferation and modulating the expression of promyogenic growth factors and myostatin in $\mathrm{C} 2 \mathrm{C} 12$ skeletal muscle cells. Endocrinology 152: 2976-2986.

9. Lee SJ, Lee YS, Zimmers TA, et al, 2010 Regulation of muscle mass by follistatin and activins. Mol Endocrinol 24: 1998-2008.

10. Angeline ME, Gee AO, Shindle M, Warren RF, Rodeo SA, 2013 The effects of vitamin D deficiency in athletes. Am J Sports Med 41: 461-464.

11. Shuler FD, Wingate MK, Moore GH, Giangarra C, 2012 Sports health benefits of vitamin D. Sports Health 4: 496-501.

12. Birge SJ, Haddad JG, 1975 25-hydroxycholecalciferol stimulation of muscle metabolism. J Clin Invest 56: 1100-1107.

13. Morton JP, Iqbal Z, Drust B, Burgess D, Close GL, Brukner PD, 2012 Seasonal variation in vitamin D status in professional soccer players of the English Premier League. Appl Physiol Nutr Metab 37: 798-802.

14. Deschenes MR, Kraemer WJ, 2002 Performance and physiologic adaptations to resistance training. Am J Phys Med Rehabil 81: Suppl 11: 3-16.

15. Beavers KM, Beavers DP, Houston DK, et al, 2013 Associations between body composition and gait-speed decline: results from the Health, Aging, and Body 
Composition study. Am J Clin Nutr 97: 552-560.

16. Oh J, Weng S, Felton SK, et al, 2009 1,25(OH)2 vitamin $\mathrm{d}$ inhibits foam cell formation and suppresses macrophage cholesterol uptake in patients with type 2 diabetes mellitus. Circulation 120: 687-698.

17. Rigby WF, Denome S, Fanger MW, 1987 Regulation of lymphokine production and human T lymphocyte activation by 1,25-dihydroxyvitamin D3. Specific inhibition at the level of messenger RNA. J Clin Invest 79: 1659-1664.

18. Simpson RU, Hershey SH, Nibbelink KA, 2007 Characterization of heart size and blood pressure in the vitamin D receptor knockout mouse. J Steroid Biochem Mol Biol 103: 521-524.

19. Artaza JN, Mehrotra R, Norris KC, 2009 Vitamin D and the cardiovascular system. Clin J Am Soc Nephrol 4: $1515-1522$.

20. Mozos I, Marginean O, 2015 Links between vitamin $\mathrm{D}$ deficiency and cardiovascular diseases. Biomed Res Int 2015: 109275.

21. Saleh FN, Schirmer H, Sundsfjord J, Jorde E, 2003 Parathyroid hormone and left ventricular hypertrophy. Eur Heart J 24: 2054-2060.

22. Al Mheid I, Patel R, Murrow J, et al, 2011 Vitamin D status is associated with arterial stiffness and vascular dysfunction in healthy humans. J Am Coll Cardiol 58: 186-192.

23. Tomaschitz A, Pilz S, Ritz E, et al, 2010 Independent association between 1,25-dihydroxyvitamin D, 25-hydroxyvitamin D and the renin-angiotensin system: The Ludwigshafen Risk and Cardiovascular Health (LURIC) study. Clin Chim Acta 411: 1354-1360.

24. Wang TJ, Pencina MJ, Booth SL, et al, 2008 Vitamin D deficiency and risk of cardiovascular disease. Circulation 117: 503-511.

25. Lee JH, O'Keefe JH, Bell D, Hensrud DD, Holick MF, 2008 Vitamin D deficiency an important, common, and easily treatable cardiovascular risk factor? J Am Coll Cardiol 52: 1949-1956.

26. Martins D, Wolf M, Pan D, et al, 2007 Prevalence of cardiovascular risk factors and the serum levels of 25-hydroxyvitamin D in the United States: Data from the Third National Health and Nutrition Examination Survey. Arch Intern Med 167: 1159-1165.

27. Muir SW, Gopaul K, Montero Odasso MM, 2012 The role of cognitive impairment in fall risk among older adults: a systematic review and meta-analysis. Age Ageing 41: 299-308.

28. Muir SW, Beauchet O, Montero-Odasso M, Annweiler C, Fantino B, Speechley M, 2013 Association of executive function impairment, history of falls and physical performance in older adults: a cross-sectional population-based study in eastern France. J Nutr Health Aging 17: 661-665.

29. Annweiler C, Montero-Odasso M, Muir SW, Beauchet O, 2012 Vitamin D and brain imaging in the elderly:
Should we expect some lesions specifically related to hypovitaminosis D? Open Neuroimag J 6: 16-18.

30. Mpandzou G, Aït Ben Haddou E, Regragui W, Benomar A, Yahyaoui M, 2016 Vitamin D deficiency and its role in neurological conditions: A review. Rev Neurol (Paris) 172: 109-122.

31. Wrzosek M, Łukaszkiewicz J, Wrzosek M, et al, 2013 Vitamin D and the central nervous system. Pharmacol Rep 65: 271-278.

32. DeLuca GC, Kimball SM, Kolasinski J, Ramagopalan SV, Ebers GC, 2013 Review: the role of vitamin D in nervous system health and disease. Neuropathol Appl Neurobiol 39: 458-484.

33. Buell JS, Dawson-Hughes B, 2008 Vitamin D and neurocognitive dysfunction: preventing decline? Mol Aspects Med 29: 415-422.

34. Zehnder D, Bland R, Williams MC, et al, 2001 Extrarenal expression of 25-hydroxyvitamin d(3)-1 alphahydroxylase. J Clin Endocrinol Metab 86: 888-894.

35. Cai Q, Tapper DN, Gilmour RF Jr, deTalamoni N, Aloia RC, Wasserman RH, 1994 Modulation of the excitability of avian peripheralnerves by vitamin $\mathrm{D}$ : relation to calbindin-D28k, calcium status and lipid composition. Cell Calcium 15: 401-410.

36. Cantorna MT, Hayes CE, DeLuca HF, 1996 1,25-Dihydroxyvitamin D3 reversibly blocks the progression of relapsing encephalomyelitis, a model of multiple sclerosis. Proc Natl Acad Sci USA 93: 7861-7864.

37. Radak Z, Taylor AW, Ohno H, Goto S, 2001 Adaptation to exercise induced oxidative stress: from muscle to brain. Exerc Immunol Rev 7: 90-107.

38. Pirotta S, Kidgell DJ, Daly RM, 2015 Effects of vitamin D supplementation on neuroplasticity in older adults: a double-blinded, placebo-controlled randomised trial. Osteoporos Int 26: 131-140.

39. Taghizadeh M, Talaei SA, Djazayeri A, Salami M, 2014 Vitamin D supplementation restores suppressed synaptic plasticity in Alzheimer's disease. Nutr Neurosci 17: 172-177.

40. Nutt D, GABA-A Receptors, 2006 Subtypes, regional distribution, and function. J Clin Sleep Med 2: Suppl: 7-11.

41. Manini TM, Clark BC, 2012 Dynapenia and aging: An update. J Gerontol A Biol Sci Med Sci 67: 28-40.

42. Acworth I, Nicholass J, Morgan B, Newsholme EA, 1986 Effect of sustained exercise on concentrations of plasma aromatic and branched-chain amino acids and brain amines. Biochem Biophys Res Commun 137: 149-153.

43. Meeusen R, Watson P, Hasegawa H, Roelands B, Piacentini MF, 2006 Central fatigue: the serotonin hypothesis and beyond. Sports Med 36: 881-909.

44. Tague SE, Smith PG, 2011 Vitamin D receptor and enzyme expressionin dorsal root ganglia of adult female rats: modulation by ovarian hormones. J Chem Neuroanat 41: 1-12. 
46. Dhesi JK, Jackson SH, Bearne LM, et al, 2004 Vitamin D supplementation improves neuromuscular function in older people who fall. Age Ageing 33: 589-595.

47. Lord SR, Clark RD, Webster IW, 1991 Physiological factors associated with falls in an elderly population. J Am Geriatr Soc 39: 1194-1200.

48. Bouillon R, Verstuyf A, 2013 Vitamin D, mitochondria, and muscle. J Clin Endocrinol Metabol 98: 961-963.

49. Redzic M, Lewis RM, Thomas DT, 2013 Relationship between 25 - hydoxyvitamin $\mathrm{D}$, muscle strength, and incidence of injury in healthy adults: a systematic review. Nutr Res 33: 251-258.

50. Ward KA, Das G, Berry JL, et al, 2009 Vitamin D status and muscle function in post-menarchal adolescent girls. J Clin Endocrinol Metab 94: 559-563.

51. Foo LH, Zhang Q, Zhu K, et al, 2009 Low vitamin D status has an adverse influence on bone mass, bone turnover, and muscle strength in Chinese adolescent girls. J Nutr 139: 1002-1007.

52. Houston DK, Cesari M, Ferrucci L, et al, 2007 Association between vitamin $\mathrm{D}$ status and physical performance: the InCHIANTI study. J Gerontol A Biol Sci Med Sci 62: 440-446.

53. Tieland M, Brouwer-Brolsma E, Nienaber-Rousseau C, van Loon L, De Groot L, 2013 Low vitamin D status is associated with reduced muscle mass and impaired physical performance in frail elderly people. Eur J Clin Nutr 67: 1050-1055.

54. Dam TT, von Mühlen D, Barrett-Connor EL, 2009 Sex-specific association of serum vitamin D levels with physical function in older adults. Osteoporos Int 20: 751-760.

55. Okuno J, Tomura S, Yabushita N, et al, 2010 Effects of serum 25-hydroxyvitamin $\mathrm{D}(3)$ levels on physical fitness in community-dwelling frail women. Arch Gerontol Geriatr 50: 121-126.

56. Wicherts IS, van Schoor NM, Boeke AJ, et al, 2007 Vitamin D status predicts physical performance and its decline in older persons. J Clin Endocrinol Metab 92: 2058-2065.

57. Mastaglia SR, Seijo M, Muzio D, Somoza J, Nuñez M, Oliveri B, 2011 Effect of vitamin D nutritional status on muscle function and strength in healthy women aged over sixty-five years. Nutr Health Aging 15: 349-354.

58. Stockton KA, Mengersen K, Paratz JD, Kandiah D, Bennell KL, 2011 Effect of vitamin D supplementation on muscle strength: a systematic review and metaanalysis. Osteoporos Int 22: 859-871.

59. Pramyothin P, Techasurungkul S, Lin J, et al, 2009 Vitamin D status and falls, frailty, and fractures among postmenopausal Japanese women living in Hawaii. Osteoporos Int 20: 1955-1962.

60. Ceglia L, Chiu GR, Harris SS, Araujo AB, 2011 Serum 25-hydroxyvitamin D concentration and physical function in adult men. Clin Endocrinol (Oxf) 74: 370-376.

61. Matheï C, Van Pottelbergh G, Vaes B, Adriaensen W,
Gruson D, Degryse JM, 2013 No relation between vitamin D status and physical performance in the oldest old: results from the Belfrail study. Age Ageing 42: 186-190.

62. Allali F, El Aichaoui S, Khazani H, et al, 2009 High prevalence of hypovitaminosis D in Morocco: relationship to lifestyle, physical performance, bone markers, and bone mineral density. Semin Arthritis Rheum 38: 444-451.

63. Garnero P, Munoz F, Sornay-Rendu E, Delmas PD, 2007 Associations of vitamin D status with bone mineral density, bone turnover, bone loss and fracture risk in healthy postmenopausal women. The OFELY study Bone 40: 716-722.

64. Hamilton B, 2010 Vitamin D and skeletal muscle. Scand J Med Sci Sports 20: 182-190.

65. Tracy BL, Ivey FM, Hurlbut D, et al, 1999 Muscle quality II. Effects Of strength training in 65- to 75-yrold men and women. J Appl Physiol 86: 195-201.

66. Bunout D, Barrera G, Leiva L, et al, 2006 Effects of vitamin $\mathrm{D}$ supplementation and exercise training on physical performance in Chilean vitamin $\mathrm{D}$ deficient elderly subjects. Exp Gerontol 41: 746-752.

67. Bischoff HA, Stähelin HB, Dick W, et al, 2003 Effects of vitamin D and calcium supplementation on falls: A randomized controlled trial. J Bone Miner Res 18: 343-351.

68. Moreira-Pfrimer LD, Pedrosa MA, Teixeira L, LazarettiCastro M, 2009 Treatment of vitamin D deficiency increases lower limb muscle strength in institutionalized older people independently of regular physical activity: A randomized double-blind controlled trial. Ann Nutr Metab 54: 291-300.

69. Pfeifer M, Begerow B, Minne H, Suppan K, FahrleitnerPammer A, Dobnig H, 2009 Effects of a long-term vitamin $\mathrm{D}$ and calcium supplementation on falls and parameters of muscle function in community-dwelling older individuals. Osteoporos Int 20: 315-322.

70. Bolland MJ, Grey A, 2015 Inconsistent data in text and tables. Osteoporos Int 26: 2713.

71. Pfeifer M, 2015 Different outcomes of meta-analyses and data inconsistency. Osteoporos Int 26: 2715-2716.

72. Rejnmark R, 2011 Effects of vitamin D on muscle function and performance: A review of evidence from randomized controlled trials. Ther Adv Chronic Dis 2: 25-37.

73. Janssen HC, Samson MM, Verhaar HJ, 2010 Muscle strength and mobility in vitamin D-insufficient female geriatric patients: a randomized controlled trial on vitamin D and calcium supplementation. Aging Clin Exp Res 22: 78-84.

74. Brunner RL, Cochrane B, Jackson RD, et al, 2008 Women's health initiative investigators. calcium, vitamin D supplementation, and physical function in the Women's Health Initiative. J Am Diet Assoc 108: 1472-1479. 
75. Gupta R, Sharma U, Gupta N, et al, 2010 Effect of cholecalciferol and calcium supplementation on muscle strength and energy metabolism in vitamin D-deficient Asian Indians: a randomized, controlled trial. Clin Endocrinol (Oxf) 73: 445-451.

76. Owens DJ, Webber D, Impey SG, et al, 2014 Vitamin D supplementation does not improve human skeletal muscle contractile properties in insufficient young males. Eur J Appl Physiol 114: 1309-1320.

77. Tomlinson PB, Joseph C, Angioi M, 2015 Effects of vitamin $\mathrm{D}$ supplementation on upper and lower body muscle strength levels in healthy individuals. A systematic review with meta-analysis. J Sci Med Sport 18: 575-580.

78. Muir SW, Montero-Odasso M, 2011 Effect of vitamin D supplementation on muscle strength, gait and balance in older adults: a systematic review and meta-analysis. J Am Geriatr Soc 59: 2291-2300.

79. Uusi-Rasi K, Patil R, Karinkanta S, et al, 2015 Exercise and vitamin $\mathrm{D}$ in fall prevention among older women: a randomized clinical trial. JAMA Intern Med 175: 703-711.

80. Javadian Y, Adabi M, Heidari B, et al, 2016 Quadriceps muscle strength correlates with serum vitamin D and knee pain in knee osteoarthritis. Clin J Pain. [Epub ahead of print]

81. Dawson-Hughes B, 2012 70th Anniversary Conference on vitamins in early development and healthy aging: impact on infectious and chronic disease' Symposium 1: Vitamins and cognitive development and performance serum 25-hydroxyvitamin D and muscle atrophy in the elderly. Proceedings of the Nutrition Society 71: 46-49.

82. Gerdhem P, Ringsberg KAM, Obrant KJ, Akesson K, 2005 Association between 25-hydroxy vitamin D levels, physical activity, muscle strength and fractures in the prospective population-based OPRA Study of Elderly Women. Osteoporos Int 16: 1425-1431.

83. Pojednic RM, Ceglia L, 2014 The emerging biomolecular role of vitamin D in skeletal muscle. Exerc Sport Sci Rev 42: 76-81.

84. Shardell M, Hicks GE, Miller RR, et al, 2009 Association of low vitamin D levels with the frailty syndrome in men and women. J Gerontol (A Biol Sci Med Sci) 64: 69-75.

85. Houston DK, Tooze JA, Davis CC, et al, 2011 Serum 25-hydroxyvitamin D and physical function in older adults: the Cardiovascular Health Study All Stars. J Am Geriatr Soc 59: 1793-1801.

86. Visser M, Deeg DJH, Puts MTE, Seidell JC, Lips P, 2006 Low serum concentrations of 25-hydroxyvitamin $\mathrm{D}$ in older persons and the risk of nursing home admission. Am J Clin Nutr 84: 616-622.

87. Bischoff-Ferrari HA, Dietrich T, Orav EJ, et al, 2004 Higher 25-hydroxyvitamin D concentrations are associated with better lower-extremity function in both active and inactive persons aged $\geq 60$ years. Am J Clin
Nutrit. 80: 752-758.

88. Ceglia L, 2009 Vitamin D and its role in skeletal muscle. Curr Opin Clin Nutr Metab Care 12: 628-633.

89. Prince RL, Austin N, Devine A, Dick IM, Bruce D, Zhu K, 2008 Effects of ergocalciferol added to calcium on the risk of falls in elderly high-risk women.Arch Intern Med 168: 103-108.

90. Pfeifer M, Begerow B, Minne H, Suppan K, FahrleitnerPammer A, Dobnig H, 2009 Effects of a long-term vitamin $\mathrm{D}$ and calcium supplementation on falls and parameters of muscle function in community-dwelling older individuals. Osteoporos Int 20: 315-322.

91. Zhu K, Austin N, Devine A, Bruce D, Prince R, 2010 A randomized controlled trial of the effects of vitamin $d$ on muscle strength and mobility in older women with vitamin D insufficiency. J Am Geriatr Soc 58: 20632068.

92. Bischoff-Ferrari HA, Dawson-Hughes B, Willett WC, et al, 2004 Effect of vitamin D on falls: a meta-analysis. JAMA 291: 1999-2006.

93. Houston DK, Tooze JA, Demons JL, et al, 2015 Delivery of a vitamin D intervention in homebound older adults using a meals-on-wheels program: A pilot study. J Am Geriatr Soc 63: 1861-1867.

94. Bischoff-Ferrari HA, Dawson-Hughes B, Orav EJ, et al, 2016 Monthly high-dose vitamin D treatment for the prevention of functional decline: A randomized clinical trial. JAMA Intern Med 176:175-183.

95. Dufour AB, Hannan MT, Murabito JM, Kiel DP, McLean RR, 2013 Sarcopenia definitions considering body size and fat mass are associated with mobility limitations: the Framingham Study. J Gerontol A Biol Sci Med Sci 68: 168-174.

96. Boucher BJ, 2012 The problems of vitamin d insufficiency in older people. Aging Dis 3: 313-329.

97. Cruz-Jentoft AJ, Baeyens JP, Bauer JM, et al, 2010 Sarcopenia: European consensus on definition and diagnosis: report of the European Working Group on sarcopenia in older people. Age Ageing 39: 412-423.

98. Mak JC, Klein LA, Finnegan T, Mason RS, Cameron ID, 2014 An initial loading-dose vitamin D versus placebo after hip fracture surgery: baseline characteristics of a randomized controlled trial (REVITAHIP). BMC Geriatr 14: 101.

99. Pioli G, Lauretani F, Pellicciotti F, et al, 2016 Modifiable and non-modifiable risk factors affecting walking recovery after hip fracture. Osteoporos Int 27: 20092016.

100. Cannell JJ, Hollis BW, Sorenson MB, Taft TN, Anderson JJ, 2009 Athletic performance and vitamin D. Med Sci Sport Exer 41: 1102-1110.

101. Koch H, Raschka C, 2000 Circannual period of physical performance analysed by means of standard cosinor analysis: a case report. Rom J Physiol 37: 51-58.

102. Erikssen J, Rodahl K, 1979 Seasonal variation in work performance and heart rate response to exercise. A 
study of 1,835 middle-aged men. Eur J Appl Physiol Occup Physiol 42: 133-140.

103. Svedenhag J, Sjodin B, 1985 Physiological characteristics of elite male runners in and off-season. Can J Appl Sport Sci 10: 127-133.

104. Maxwell JD, 1994 Seasonal variation in vitamin D. Proc Nutr Soc 53: 533-543.

105. Kopeć A, Solarz K, Majda F, Słowińska-Lisowska M, Mędraś M, 2013 An evaluation of the levels of vitamin $\mathrm{D}$ and bone turnover markers after the summer and winter periods in polish professional soccer players. J Hum Kinet 38: 135-140.

106. Storlie DM, Pritchett K, Pritchett R, Cashman LM, 2011 12-week vitamin D supplementation trial does not significantly influence seasonal $25(\mathrm{OH}) \mathrm{D}$ status in male collegiate athletes. Int J Health Nutr 2: 8-13.

107. Galan F, Ribas J, Sánchez - Martinez PM, Calero T, Sánchez AB, Muñoz A, 2012 Serum 25 - hydroxyvitamin D in early autumn to ensure vitamin D sufficiency in mid - winter in professional football players. Clin Nutr 31: 132-136.

108. Holick MF, 2003 Vitamin D: a millennium perspective. J Cell Biochem 88: 296-307.

109. Koundourakis NE, Androulakis NE, Malliaraki N, Margioris AN, 2014 Vitamin D and exercise performance in professional soccer players. PLoS ONE 9: e101659.

110. Barker T, Henriksen VT, Martins TB, et al, 2013 Higher serum 25-hydroxyvitamin D concentrations associate with a faster recovery of skeletal muscle strength after muscular injury. Nutrients 5: 1253-1275.

111. Mowry DA, Costello MM, Heelan KA, 2009 Association among cardiorespiratory fitness, body fat, and bone marker measurements in healthy young females. J Am Osteopath Assoc 109: 534-539.

112. Forney LA, Earnest CP, Henagan TM, Johnson LE, Castleberry TJ, Stewart LK, 2014 Vitamin D status, body composition, and fitness measures in collegeaged students. J Strength Cond Res 28: 814-824.

113. Hamilton B, Whiteley R, Farooq A, Chalabi H, 2014 Vitamin D concentration in 342 professional football players and association with lower limb isokinetic function. J Sci Med Sport 17: 139-143.

114. Ardestani A, Parker B, Mathur S, et al, 2011 Relation of vitamin D level to maximal oxygen uptake in adults. Am J Cardiol 107: 1246-1249.

115. Fitzgerald JS, Peterson BJ, Warpeha JM, Wilson PB, Rhodes GS, Ingraham SJ, 2014 Vitamin D status and $\mathrm{V}$ [combining dot above]O2peak during a skate treadmill graded exercise test in competitive ice hockey players. J Strength Cond Res 28: 3200-3205.

116. Dubnov-Raz G, Livne N, Raz R, Rogel D, Cohen AH, Constantini NW, 2014 Vitamin D concentrations and physical performance in competitive adolescent swimmers. Pediatr Exerc Sci 26: 64-70.

117. Wilson PB, Fitzgerald JS, Ingraham SJ, 2013 Relation- ship between serum 25-hydroxyvitamin D status and cardiorespiratory fitness: Findings from the National Health and Nutrition Examination Survey. Int J Cardiol 168: 3112-3113.

118. Macdougall JD, Hicks AL, Macdonald JR, Mckelvie RS, Green HJ, Smith KM, 1998 Muscle performance and enzymatic adaptations to sprint interval training. J Appl Physiol 84: 2138-2142.

119. Dahlquist DT, Dieter BP, Koehle MS, 2015 Plausible ergogenic effects of vitamin D on athletic performance and recovery. J Int Soc Sports Nutr 12: 33.

120. Gorkin Z, Gorkin MJ, Teslenko NE, 1938 The effect of ultravioletirradiation upon training for $100 \mathrm{~m}$ sprint. Fiziol Zh USSR 25: 695-701.

121. Lehmann G, Mueller EA, 1944 Ultraviolet irradiation and altitude fitness. Luftfahrtmedizin 9: 37-43.

122. Allen R, Cureton T, 1945 Effects of ultraviolet radiation on physical fitness. Arch Phys Med 10: 641-644.

123. Sigmund R, 1956 Effect of ultraviolet rays on reaction time in man. Strahlentherapie 101: 623-629.

124. Rosentsweig J, 1967 The effect of a single suberythemic biodose ofultraviolet radiation upon the strength of college women. J Assoc Phys Ment Rehabil 21: 131-133.

125. Rosentswieg J, 1969 The effect of a single suberythemic biodose ofultraviolet radiation upon the endurance of college women. J Sports Med Phys Fitness 9: 104-106.

126. Cheatum BA, 1968 Effects of a single biodose of ultraviolet radiationupon the speed of college women. Res Q 39: 482-485.

127. Close GL, Russell J, Cobley JN, et al, 2013 Assessment of vitamin D concentration in non-supplemented professional athletes and healthy adults during the winter months in the UK: implications for skeletal muscle function. J Sports Sci 31: 344-353.

128. Wyon MA, Koutedakis Y, Wolman R, Nevill AM, Allen N, 2014 The influence of winter vitamin D supplementation on muscle function and injury occurrence in elite ballet dancers: a controlled study. J Sci Med Sport 17: 8-12.

129. Wyon MA, Wolman R, Nevill AM, et al, 2015 Acute effects of vitamin D3 supplementation on muscle strength in judoka athletes: A randomized placebocontrolled, double-blind trial. Clin J Sport Med 26: 279-284.

130. Close GL, Leckey J, Patterson M, et al, 2013 The effects of vitamin $\mathrm{D}(3)$ supplementation on serum total $25[\mathrm{OH}] \mathrm{D}$ concentration and physical performance: a randomised dose-response study. Br J Sports Med 47: 692-696.

131. Jastrzębski Z, 2014 Effect of vitamin D supplementation on the level of physical fitness and blood parameters of rowers during the 8-week high intensity training. Facicula Educ Fiz şi Sport 2: 57-67.

132. Jastrzębska M, Kaczmarczyk M, Jastrzębski Z, 2016 The effect of vitamin d supplementation on training 
adaptation in well trained soccer players. Strength Cond Res 30: 2648-2655.

133. Lee DM, Tajar A, Pye SR, et al, EMAS study group, 2012 Association of hypogonadism with vitamin D status: the European Male Ageing Study. Eur J Endocrinol 166: 77-85.

134. Wehr E, Pilz S, Boehm BO, Marz W, ObermayerPietsch B, 2010 Association of vitamin D status with serum androgen levels in men. Clin Endocrinol 73: 243-248.

135. Nimptsch K, Platz EA, Willett WC, Giovannucci E, 2012 Association between plasma 25-OH vitamin D and testosterone levels in men. Clin Endocrinol (Oxf) 77: 106-112.

136. Heijboer AC, Oosterwerff M, Schroten NF, et al, 2015 Vitamin D supplementation and testosterone concentrations in male human subjects. Clin Endocrinol (Oxf) 83: 105-110.

137. Pilz S, Frisch S, Koertke H, et al, 2011 Effect of vitamin D supplementation on testosterone levels in men. Horm Metab Res 43: 223-225.

138. Wang N, Han B, Li Q, et al, 2015 Vitamin D is associated with testosterone and hypogonadism in Chinese men: Results from a cross-sectional SPECT-China study. Reprod Biol Endocrinol 13: 74-78.

139. Tak YJ, Lee JG, Kim YJ, et al, 2015 Serum 25-hydroxyvitamin D levels and testosterone deficiency in middle-aged Korean men: a cross-sectional study. Asian J Androl 17: 324-328.

140. Morley JE, 2012 Sarcopenia in the elderly. Fam Pract Suppl 1: i44-i48.

141. Roubenoff R, 2000 Sarcopenia: a major modifiable cause of frailty in the elderly. J Nutr Health Aging 4: 140-142.

142. Marcell TJ, 2003 Sarcopenia: causes, consequences, and preventions. J Gerontol A Biol Sci Med Sci 58: M911-916.

143. Roth SM, Ferrell RF, Hurley BF, 2000 Strength training for the prevention and treatment of sarcopenia. J Nutr Health Aging 4: 143-155.

144. Forbes GB, 1999 Longitudinal changes in adult fatfree mass: influence of body weight. Am J Clin Nutr 70: 1025-1031.

145. Hughes VA, Frontera WR, Roubenoff R, Evans WJ, Fiatarone-Singh MA, 2002 Longitudinal changes in body composition in older men and women: role of body weight change and physical activity. Am J Clin
Nutr 76: 473-481.

146. Gallagher D, Ruts E, Visser M, et al, 2000 Weight stability masks sarcopenia in elderly men and women. Am J Physiol Endocrinol Metab 279: E366-E375.

147. Park S, Ham JO, Lee BK, 2014 A positive association of vitamin D deficiency and sarcopenia in 50 year old women, but not men. Clin Nutr 33: 900-908.

148. Anagnostis P, Dimopoulou C, Karras S, Lambrinoudaki I, Goulis DG, 2015 Sarcopenia in post-menopausal women: Is there any role for vitamin D? Maturitas 82: $56-64$.

149. Lappe JM, Binkley N, 2015 Vitamin D and sarcopenia/ falls. J Clin Densitom 18: 478-482.

150. Kim MK, Baek KH, Song KH, et al, 2011 Vitamin D deficiency is associated with sarcopenia in older Koreans, regardless of obesity: the Fourth Korea National Health and Nutrition Examination Surveys (KNHANES IV) 2009, 2011. J Clin Endocrinol Metab 96: 32503256.

151. Zhang Y, Leung DY, Richers BN, Liu Y, Remigio LK, Riches DW, Goleva E, 2012 Vitamin D inhibits monocyte/macrophage proinflammatory cytokine production by targeting MAPK phosphatase-1. J Immunol 188: 2127-2135.

152. Calton EK, Keane KN, Newsholme P, Soares MJ, 2015 The impact of vitamin D levels on inflammatory status: A systematic review of immune cell studies. PLoS One 10: e0141770.

153. Tidball JG, 2002 Interactions between muscle and the immune system during modified musculoskeletal loading. Clin Orthop Relat Res 403: S100-109.

154. Tidball JG, 2005 Inflammatory processes in muscle injury and repair. Am J Physiol Regul Integr Comp Physiol 288: R345-353.

155. Smith C, Kruger MJ, Smith RM, Myburgh KH, 2008 The inflammatory response to skeletal muscle injury: illuminating complexities. Sports Med 38: 947-969.

156. Fatouros IG, Jamurtas AZ, 2016 Insights into the molecular etiology of exercise-induced inflammation: opportunities for optimizing performance. J Inflamm Res 9: 175-186.

157. Dougherty KA, Dilisio MF, Agrawal DK, 2016 Vitamin $\mathrm{D}$ and the immunomodulation of rotator cuff injury. $\mathrm{J}$ Inflamm Res 9: 123-131.

158. Ke CY, Yang FL, Wu WT, et al, 2016 Vitamin D3 reduces tissue damage and oxidative stress caused by exhaustive exercise. Int J Med Sci 13: 147-153. 